infection are duly adopted, it is impossible to say haw long the person and clothes of a nurse may remain a source of danger. A very valuable contribution on this subject is made by Ahlfeld in the Centralblatt fiir Gynäkologie, 3Ist May, 1880. In this article the author protests against the State regulation adopted in Saxony, which compels a mid. wife, when a case of puerperal fever occurs in her practice, to cease from it for a stated period, instead of insisting upon rapid and thorough disinfection.

Nurses and midwives deserve great consideration at the hands of the obstetrical branch of our profession. It is our duty to provide them with sound instruction in regard to the use and application of disinfectants arid antiseptics. By our so doing, not only will they as a class be greatly benefited, but lying-in women will be placed in much greater safety than by unjustly punishing unfortunate midwives.

It is to be regretted that the mover of the famous discussion on puerperal fever in the London Obstetrical Society in 1875 , should, in his summing-up speech, have met the protest against the special act of injustice practised in the name of law upon midwives at that time, by something very like a sneer. It would be much more to the purpose to meet the question boldly as Ahlfeld does, and demonstrate to nurses that time is only a very uncertain element in disinfection, and that cleanliness and antiseptic applications are the only measures by which safety can be secuired.

In regard : to the prevention of puerperal septicamia in maternity hospitals' by strict application of antiseptics, and more particularly of carbolic acid, I may be allowed to refer to the successful practice of Dr. Lucas-Championniére in the Cochin Hospital of Paris, as recorded by Dr. Amédée Doléris, p. 294, ct scq., in his work entitled La Fïévre Puerpérale, Paris, I880. There seems to me no good reason to doubt that with proper care as to hygiene and antiseptics, patients treated at a maternity hospital ought to be as free from septicremia as those attehded in the best private houses.

In conctusion, $\mathbf{I}$ would wish to express my belief: $\mathbf{1}$. That the diligent and intelrigent employment of antiseptic precautions and apptrances, good ventilátion, and extreme cleanliness are capable of very Jargely diminishing the occurrence of septiciemia, bcth in maternity tospitals and -in private practice; and 2. That, if antiseptics are carefully and systematically employed, there should be no case of commanication of the disorder from one patient to another by the medical attendant, even when he performs to the sick person all the duties that are incumbent upon him as a medical adviser. It is always, howcver, to be understood that the doctor restricts himself to his oven duties, and does not encroach upon those of the nurse; and that his measures to secure perfect antisepsis shall be thorough in all cases, when there is the slightest suspicion of septicxmia. It follows also, if these views are correct, that the recommendation so frequently given to an obstetrician, to leave his practice in case he meets with puerperal fever, is both unnecessary and unsatisfactory, inasmuch as it tends to the neglect of the most $r$ tiable meastres of safety, namely, constant attention to cieanliness, and thorough and complete disinfection; whilst it puts upon the obstetrician a burden that is too heavy for him to bear, and which, indeed, is not borne by the very people who are loudest in recommending its necessity.

\section{ON TOBACCO-AMBLYOPIA.*}

\section{By JOSEPH NELSON, M.D.}

THAT cases of tobacco-amblyopia are not of unfrequent occurrence in Austria, is evident from statistics collected by Drs. Reuss and Fuchs; for, according to them, no fewer than 153 cases, all men, are recorded from Dr. Arlt's Klinik, during the eleven years ending 1876. During the past twenty months, I have had the opportunity of sceing nearly all the cases which presented themselves at this Klinik; and, through the kindness of Professor Arlt, I was allowed to investigate and have the charge of those cases which were able and willing to undergo treatment. Unfortunately for observation, however, many of these people lived far from Vienna. Of those who did remain in town, twenty-six afforded me material for the following notes.

Inasmuch as the bulk of my notes only confirm what has already been written on the subject by Leber, Hutchinson, Nettleship, and other authors, I shall confine myself as much as possible to a statistical $r:$ sut nit of my investigatious. The patients were all men in good health, and between forty and sixty-six years of age, except three. The roungest w: s twenty-seven years old.

Failure of sight was, in most cases, about one-tenth, never so reduced

* Read in the Section of Ophthalmology at the Annual Meeting of the British Medical Association in Cambridge, August 1880 that the patient could not go about readily. In the majority; sight failed in from two to six months; in a few, from two to six weeks. The duration of failure bore no constant relation to the degree of amblyopia, or to perception of colours. They saw better in the evening, or in subdued light. During daylight, especially bright sunlight, everything appeared fogged or clouded. All smoked; the small. est amount of tobacco consumed during the day being over half an ounce, the largest quantity an ounce and a half. In only four instances were patients free drinkers, in addition to the abuse of tobacco. I may remark that these four cases were the longest in seeking advice: or that their sight failed perhaps more gradually than in other cases; thus bringing to my mind Hutchinson's suggestion, that alcohol:may have a balancing or counteracting effect upon tobacco (Royal London Oph thalmic Hospilal Reports, vol. viii, p. 458). I should state that these people drank wine and spirits, not beer.

Failure of sight was generally equal in both eyes; there was never any marked difference that could not be accounted for by refraction, opacity, or other evident cause.

On testing with Holmgren's wools or colours of large surface, the colour-sense was, as a rule, normal; but, on testing with small coloured discs of six millimitres or less, on a black background, like Donders's discs, more or less impairment of colour-sense was present in the majority of cases. For the different colours, especially red and green, the perimeter almost invariably revealed a scotoma between the blind spot and the fixation-point, and embracing both. In all cases in which I tested, I found much the same shape and size of scotoma in both eyes. The peripheric portion of the field for colours was normal, and the field for white neither contracted or concentrated; thus differing from other forms of amblyopia-ataxic, cerebral, hysterical, glaucomatous, neuritic, and hereditary. The scotomata were negative, and differed much in intensity. In some, the square (of ten millimétres) would change colour or become indistinct, whilst in others the colour would be completely lost.

We have here a number of central scotomata, embracing both the fixation point and the blind spot; and I would ask, How do these scotomata begin? There are two possibilities: 1 . They may begin at the fixation-point, and extend outwards to the blind spot; or, 2. They may begin at the blind spot, and extend towards the fixation point. The former, according to authors (Leber, Nettleship, Treitel) is that generally accepted; but, from the cases which came under my observation, I would hold that the scotoma begins at the blind spot, and extends towards the fixation point. The points upon which I rest are five: I. The gradual failure of sight; 2 . The shape of the scotoma; 3. The density; 4. The manner of receding; 5. The fact of seeing cases where fixation-point is free.

I. If the scotoma hegan at the fixation-point, the central vision would probably become at once so bad as to oblige the patient to seek medical advice, and we would then very often find a scotoma which had not yet reached the blind spot. But, as the scotoma sets in at the disc, it will at first: not much interfere with sight, and the patient will only seek aid when the scotoma has extended to and embraced the macula. For this reason, we always find the scotoma so large, as to include both fixation-point and blind spot.

2. The scotoma was often of an irregular pear-shape; but, of whatever shape, the base or broad part was always at the blind spot, whilst the apex or narrow portion was at the fixation:point.

3. The scotorma was invariably denser at and towards the blind spot than at the fixation-point; in fact, the density increased from the fixation-point towards the blind spot.

4. It is a matter of fact that a scotoma may disappear, especially under judicious treatment, such as leaving off smoking, rest of the eyes, etc. I have myself had four cases, all well-marked scotomata, in which they completely disappeared. As regards the manner of receding or disappearing, I would direct attention to three cases where second and even third observations were made, and the changes-the decrease in size, position, shape, and density-are noted. These changes are, I think, very suggestive; so much so, that I am inclined to think that, if we could only cxamine a tobacco-case at an early stage, we should find a young scotoma growing from the blind spot-its base-and extending towards the fixation-point, but stopping short of it. The opportunity of examining such a case is, however, very unlikely to occur, inasmuch as the patient will not complain until the macula is reached, and sight interfered with.

5. One of the perimeter charts shows a scotoma of the usual shape and position, except that it does not reach the fixation-point. This was in a case of six months' failure, and was probably a receding scotoma; at any rate, it is a case where the fixation-point. is free.

The density of the scotoma does not seem to hold any proportion to acuity of vision, for, in Case XIV, with dense scotoma embracing the 
fixation-point, sight was reduced to only one-third; whilst, in Case IX, where scotoma was comparatively slight, sight was lowered to onetwelfth of normal. ${ }^{*}$ The density, however, appears to hold a proportion to colour-perception; for, in Case IX, the smallest discs were fairly recognised, whilst, in Cases XIV and XXV, and others, the colourperception was markedly impaired. The ophthalmoscope showed, in most cases, the discs hyperæmic, and their margin blurred. In some cases, the temporal quadrants of the discs had an indistinct paleness; and were sometimes atrophic-like, with fewer of the small vessels. In a few cases only did I observe white striæ along the vessels on the disc. Sometimes, the ophthalmoscopic appearances were nil.

The foregoing are the symptoms, subjective and objective, by which tobacco-amblyopia may be known. The first to describe this disease was Arlt, but then no perimeter was in use. The only symptoms which he could find were nyctalopia and ophthalmoscopic changes; the former, being the more striking, he termed it accordingly; and, to distinguish it from other forms of nyctalopia, he added the term retinitis (retinitis nyctalopia), inasmuch as he observed a slight change round the disc. The only cases for which this disease might be mistaken without the aid of the ophthalmoscope, and in which nyctalopia is present, are nuclear and perinuclear cataract; but the fact of the latter dating from childhood would suffice to prevent such a mistake.

In the absence of the ophthalmoscope and perimeter, a general practitioner might be at a loss to distinguish this from other forms of amblyopia, in which external examination shows nothing, or nothing sufficient to account for failure of sight; as, for instance, simple glaucoma, commencing senile cataract, atrophy of the disc, etc.; ritinitis and choroiditis; but, in all these cases, there is likely to be a very marked difference in the degree of sight in each eye, and no nyctalopia present. As to this nyctalopia, or better sight by subdued light, it certainly would appear that, in some cases, the patients really do see better. In one case (a coachman), the man said, "By daylight, when driving my master, I cannot see the numbers on the houses; but, when the sun goes down, and towards evening, I can make out the numbers distinctly". That acuity of vision is not really raised to any important degree, can be readily shown by Leber's experiment (Gräfe und Sämisch's Handbuch, vol. v, part 2, p. 832). Now, holding that the acuity of vision is not materially raised, and at the same time owning that the patients see better by subdued light, needs explanation. It has been accounted for (Nettleship) by partial dilatation of the pupil, which takes place in subdued light, as observed in cases of nuclear cataract; but I cannot conceive how the cases are analogous. Dr. Fuchs of Vienna thinks it may be accounted for as follows. The patients say that, the brighter the light, the more clouded, veiled, and indistinct is the object they look at; whereas, by dull light, the object is less clouded and more distinct. May the explanation then be that, by subdued light, the cloud or veiling is less evident, the contrast less marked, and, therefore, the patient thinks he sees better?

Provided the patient gives up or reduces the use of tobacco, the progress is very favourable, and recovery may follow without any systematic treatment. This has been shown by Hutchinson and Nettleship, who wrote to a large number of such cases; and the replies showed that "a large majority had quite recovered, but scarcely any had got worse". A regular systematic treatment will, I believe, materially hasten recovery. With two exceptions, those cases which submitted to treatment made what I may be allowed to term "perfect recovery"; and in those who remained under observation for only a short time, the improvement in vision was very marked during the first few days; especially was this early and marked improvement observed in those patients who were treated with subcutaneous injections of strychnine. In those cases which were tested by Forster's photometer, the lightsense was found to be normal ; in no case was it reduced. This fact, together with the complete absence of ophthalmoscopic changes in the retina, indicates that the affection does not lie there, nor is there any evidence which points to the brain as the origin.

That the disease is seated in the optic nerve may be inferred from the fact that in the beginning we find very slight ophthalmoscopic changes, and, later, the degree of atrophy which follows at the outer portion of the disc appears considerable compared with the slight degree of congestion which had been observed in the disc, but quite natural if we assume a stronger inflammation and atrophy behind and travelling forwards.

Now, owing to want of anatomical investigation in such cases, one must lean upon observations; and, if the charts which the perimeter has given me in the foregoing cases be correct, and if $I$ may be allowed to deduce therefrom the mannet of growth and disappearance of the scotoma, the result should, I think, assist to support the theory of

* Treitel found scotoma sometimes evident in normal vision. Gräfe's Archiv, vol. $\mathrm{xxv}$, part II, p. 98 .
Leber-viz, that we have a retrobulbar neuritis, confined to certain fibres which lie superficial, and close to the temporal side of the sheath, and which simply bend over into the retina (Michel) and run outwards in a horizontal direction towards the macula.

\section{THERAPEUTIC MEMORANDA.}

\section{TOLERATION OF OPIUM IN THE INFANT.}

IN the JOURNAL of May. $5^{\text {th }}$ I recorded a case, showing such a toleration of opium in an infant of four months as I had hitherto deemed incompatible with life at such an age, and would now communicate further particulars concerning the same.

The child at birth had been plump and healthy, but soon afterwards, from the use of improper food, he was seized with colicky pains and cos. tiveness. Besides laxatives, carminatives and then opiates were given and increased, until, at the age of four months, the infant was getting (in drachm-doses) from six to eight drachms of laudanum in the twenty-four hours. During that period, the child gradually lost flesh, and, when I first saw him, was so emaciated that his ribs were prominent and the abdominal walls retracted. Theface and limbs were shrunken correspondingly, and the legs were constantly flexed on the abdomen, save when the child was narcotised with not less than fifty drops of laudanum, which dose only afforded relief for a period varying from three to four hours. There was no vomiting, cough, or other sign of disease, and the infant took the breast with avidity. I advised the mother to reduce the dose of laudanum steadily by ten drops per diem. Thinking that a small quantity of cod-oil might assist the child to regain flesh, I ordered a teaspoonful to be given thrice daily, and a mixture containing bismuth and pepsin. This, with an occasional laxative at first, constituted all the treatment. Whereas, before that time, diminution of the opiate draught was followed by an access of pain, it was now possible gradually to withdraw the laudanum $\rightarrow$ so that, in less than a month, it was entirely stopped, and the child lost its painfully emaciated appearance. In two months, he had completely recovered his flesh and spirits; the treatment was discontinued, and the infant was fed with breast-milk alone. The bowels now move more regularly, without any artificial stimulus. The quondam patient sleeps soundly, minuts his wonted narcotic; and, as far as I can see, there is no sign of mental infirmity or defect.

The foregoing case appears to me interesting in several respects : I. The toleration of so large a quantity of opium by a child of four months old ; 2. The persistence of appetite for a period of nearly three months, during which the sedative was employed; and 3. The entire recovery of the patient, as shown by his rapid increase in weight, his release from pain and costiveness, and the return of the buoyant spirits natural to healthy infancy.

$$
\text { J. Mackenzie Booth, M.A., M.D., Aberdeen. }
$$

THE INUNCTION OF CASTOR-OIL AS A PURGATIVE. I wAS much surprised on reading Dr. McNicoll's remarks concerning the purgative effects of castor-oil, when applied locally to the bowels.

During a long and extensive practice, I have frequently seen castoroil applied topically to the chest, as a remedy for bronchial and other pulmonary affections, minus the inunction: but have, in no single instance, observed such cathartic effects which, on the hypothesis of capillary absorption, would, according to Dr. McNicoll, probably take place.

It is known to nearly every practitioner that the peristalt $c$ action of the bowels practically ceases, in non-zymotic cases, during the period of confinement to bed, which is necessitated in most acute diseases. I assume, therefore, in this case, the same condition would exist, which would explain the cause of the constipation; and am inclined to think that the effects described were due more to the atousal of peristaltic activity by the friction or stimulus of "the warm hand over the abdomen", than the agent employed in the process.

I have frequently taken advantage of the physiological fact above alluded to, and have often been rewarded by results equally as success. ful as those of Dr. McNicoll, by the simple inunction of warm olive-oil, or any other fixed oil which might be at hand, to lubricate the skin durìng the process; and I feel persuaded that, if Dr. McNicoll will pursue his investigation by substituting olive or ather fixed cill, he will find himself equally as successful as if castor-oil had been the medium employed. Jow Kershaw, F.R.C.S.E., L.K.C.P., etc. Highlands, Royton, near Oldhom.

IT is quite possible that the abdominal friction involved in the inunction of castor-oil may have produced purgation in the case q:0:ed by 